\title{
PERANCANGAN INFOGRAFIS TUTORIAL COMIC PREPARATION UNTUK KOMIKUS PEMULA
}

\author{
Akhmad Fadly \\ Pascasarjana Desain, Institut Seni Indonesia Yogyakarta \\ akhmad.fadly019@gmail.com
}

\begin{abstract}
The comic development in Indonesia is getting into the productive zone marked by the emergence of digital-comic platforms as the means to compile comic works. These platforms promises financial appreciation to comic artists whose comics are published on the platforms. The existence of the facility and the positive appreciation of the comic platforms stimulates the emergence of the novice comicartists. Sadly, most of them fail to fulfill the required standard of creating a digitalcomic work. In fact, they crucially need proper information and education about the initial steps to do in order to be a comic artist fulfilling the standard of digital-comic platforms. The study employs the method of Visual-Communication-Design Triadik thinking by Sumbo Tinarbuko to map the designing process which is sturdy, palpable, and covering all the required elements in the design. This designing method refers to the modern designing method which comprises four stages namely identification, analysis, synthesis, and evaluation. The tutorial content is a creation material of 4 pre-production aspects of comic works which are outline, character design, universe, and gimmick. The visual message is delivered through the character illustration design of SAMPANA comic by applying the different theme color in the illustration as the variation for each material. The utilized designing material is info-graphic and poster.
\end{abstract}

Key words: tutorial, digital comic

\begin{abstract}
Abstrak: Perkembangan komik di Indonesia semakin menempati wilayah produktifnya, ditandai dengan mulai bermunculan platform komik digital sebagai wadah yang menghimpun karya komik, platform komik digital juga menyanggupi untuk memberi apresiasi berupa materi yang menjanjikan kepada komikus yang karyanya berhasil terbit di platform mereka. Dampak kemudahan serta apresiasi yang baik dari platform komik ini membuat semakin ramai pula komikus-komikus pemula bermunculan, namun tidak sedikit yang belum memenuhi standar yang baik dalam menghasilkan karya komik digital, mereka masih membutuhkan informasi dan edukasi mengenai langkah awal yang dilakukan, untuk menjadi komikus yang karyanya memenuhi standar industri platform komik digital. Metode perancangan menggunakan metode Triadik berfikir desain komunikasi visual oleh Sumbo Tinarbuko untuk memetakan proses perancangan secara kokoh, jelas dan mengcover semua elemen yang dibutuhkan dalam perancangan. Metode perancangan ini mengacu pada metode desain modern yang meliputi empat tahapan, yaitu identifikasi, analasis, sintesis, dan evaluasi. Konten tutorial merupakan materi pembentukan 4 aspek pra produksi berkarya komik, diantaranya adalah Outline, Character Design, Universe, dan Gimmick. Pesan visual disampaikan melalui desain ilustrasi karakter dari komik SAMPANA, dengan penerapan tema warna yang berbeda pada ilustrasi sebagai variasi untuk masing-masing materi. Media perancangan yang digunakan adalah Infografis dan Poster.

Kata kunci: Tutorial, komik digital
\end{abstract}

\section{Latar Belakang Masalah}

Perkembangan komik di Indonesia dilihat dari beberapa fase semakin pesat perkembangannya. Komik Digital baru baru ini sudah mulai populer di kalangan penikmat komik di Indonesia, bisa dibaca secara gratis dan diakses dengan mudah melalui smartphone. Tak hanya para penikmat komik saja yang terhibur namun para kreator-kreator komik baru juga mulai bermunculan karena hadirnya komik 
digital sebagai sarana berkarya komik dengan mudah, Para komikus tidak perlu lagi ambil pusing untuk mencetak komik mereka dan bagaimana karya mereka sampai di masyarakat, tidak hanya itu platform komik digital atau platform webcomic juga menyanggupi untuk memberi apresiasi dana yang cukup mumpuni kepada para komikus yang karyanya tayang di platform mereka.

Dampak kemudahan serta apresiasi yang baik dari platform komik digital serta akses yang mudah dalam sosial media seperti Facebook dan Instagram, apalagi masyarakat sekarang mampu berkomunikasi dengan baik melalui smartphone. Maka semakin banyak pula komikus-komikus pemula bermunculan, mereka semakin tertarik berkarya komik, dan profesi komikus pun tidak lagi dipandang sebelah mata. Hal ini akan membantu perekonomian serta perkembangan industri kreatif di Indonesia, khususnya pada bidang komik dan pengembangan Intellectual Property (IP).

Semakin banyak komikus pemula bermunculan, namun tidak sedikit yang belum memenuhi standar yang baik untuk karya komik digital. Tidak sedikit pula lamaran kerja komikus yang di kembalikan karena tidak memenuhi standar komik untuk di tayangkan. Sebagian besar kegagalan komikus pemula terletak pada bagian cerita atau storytelling.

"Gambarnya keren, tapi ceritanya ngaco, ya kami balikin untuk dirombak kembali ceritanya" (Mohammad Adesa P/Editor Ciayo Comic). "Kalau gambarnya bagus tapi ceritanya jelek, kami akan coba partner-kan dengan yang ceritanya bagus tapi gambarnya di bawah ratarata, atau mau nggak gambarin ceritanya orang lain?" (Andik Prayogo/Director ReOn Comic). "Comic is not about good artworking, Comic is about good storytelling" (Sweta

\section{Kartika/Professional Comic Artist)}

Untuk saat ini tutorial untuk membuat komik khususnya dalam pengembangan storytelling sangat jarang, kebanyakan tutorial yang beredar di toko buku maupun media sosial berkonsentrasi pada teknik menggabarnya saja, oleh karena itu dalam kesempatan kali ini penulis akan merancang tutorial praproduksi bekarya komik melalui media sosial untuk komikus pemula berdasarkan pengalaman artistik penulis sebagai komikus professional.

\section{Rumusan Masalah}

Bagaimana komunikasi visual tutorial Comic Preparation untuk komikus pemula?

\section{Tujuan dan Manfaat}

\section{Tujuan}

Tujuan dari perancangan ini adalah merancang infografis tutorial Comic Preparation untuk komikus pemula yang memiliki daya tarik secara visual. Sehingga dapat mengedukasi dan memotivasi para komikus pemula untuk berkarya komik dengan standar storytelling industri komik digital.

\section{Manfaat}

1) Perancangan Infografis tutorial Comic Preparation untuk komikus pemula dapat menjadi refrensi dan sumber penggalian ide bagi mahasiswa desain komunikasi visual.

2) Perancangan Infografis tutorial Comic Preparation untuk komikus pemula dapat menjadi refrensi dan alternatif solusi permasalahan desain komunikasi visual bagi desainer komunikasi visual.

3) Perancangan Infografis tutorial Comic Preparation untuk komikus pemula dapat menjawab kebutuhan komikus pemula terkait kebutuhan akan akses tutorial untuk merancang cerita komik.

4) Perancangan Infografis tutorial Comic Preparation untuk komikus pemula dapat mendukung industri kreatif di Indonesia dalam potensi meningkatkan kualitas cerita komik di Indonesia.

\section{Metode Perancangan}

Keseluruhan proses Perancangan tutorial Comic Preparation untuk komikus pemula mengaplikasikan metode berfikir desain komunikasi visual. Triadik berfikir desain komunikasi visual oleh Sumbo Tinarbuko digunakan sebagai grand teory untuk memetakan proses perancangan secara kokoh, jelas dan mengcover semua elemen yang di butuhkan dalam perancangan. Triadik berfikir desain komunikasi visual menjadi dasar kontrol perancangan serta sebagai panduan menyusun konsep karya secara proporsional dengan menekankan koneksi antara pendekatan teori, 
permasalahan desain komunikasi visual dan target audience yang di tuju. (Tinarbuko, 2017: $55)$.

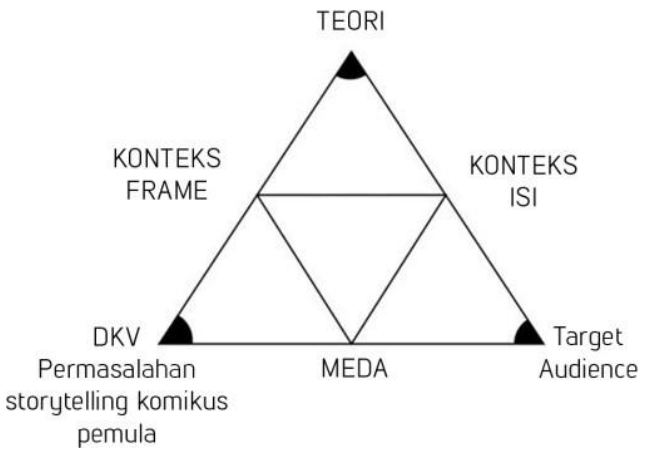

\section{Triadik berfikir desain komunikasi visual oleh Sumbo Tinarbuko}

Metode perancangan yang digunakan pada perancangan ini mengacu pada metode desain modern yang meliputi empat tahapan, yaitu: identifikasi, analasis, sintesis dan evaluasi. Tahapan-tahapan perancangan dapat digambarkan sebagai berikut:

\section{Idenitifikasi}

Identifikasi permasalahan Storytelling komikus pemula.

Target audience primer diidentifikasi sebagi komikus-komikus pemula baik pria maupun wanita dalam rentang usia produktif. Sedangkan target audience sekunder adalah seluruh masyarakat indonesia dari segala umur yang tertarik untuk terjun ke industri kreatif komik digital. Karakteristik target audience primer dalam perancangan ini adalah: a) Demografis

Remaja pria dan wanita dalam rentang usia produktif berkarya komik dengan perkiraan usia 15-30 tahun. Tingkat perekonomian menengah menengah dan menengah keatas. Tingkat pendidikan kelulusan sekolah menengah pertama, sekolah menengah atas, perguruan tinggi, dan sederajat.

b) Geografis Tinggal di wilayah perkotaan negara Indonesia.

c) Psikografis Memiliki rasa ingin tahu yang besar dan peduli terhadap kualitas berkarya komik.

d) Behaviour
Remaja pria dan wanita, komikus pemula yang up-to-date dan mengikuti trend, memiliki media sosial, pengguna aktif internet.

Sedangkan target audience sekunder dalam perancagan ini adalah seluruh masyarakat Indonesia yang tertarik untuk terjun di dunia industri kreatif komik digital.

\section{Analisis}

Menentukan Konteks Perancangan

PERMASALAHAN + TEORI $=$
KONTEKS

Tahap penentuan konteks perancangan dalam triadik DKV ditentukan melalui proses menghubungkan antara titik permasalahan dengan landasan teori. Identifikasi permasalahan Storytelling pada komikus pemula yang telah dilakukan sebelumnya lalu dipadukan dengan teori-teori yang ada untuk kemudian dianalisis menjadi konteks perancangan. Analisis ini dilakukan agar frame/batasan perancangan menjadi jelas, sehingga dapat menjawab rumusan permasalahan. Konteks perancangan dianalisis dengan metode $5 \mathrm{~W}+1 \mathrm{H}$ (What, Who, When, Why, dan How) adalah sebagai berikut.

\section{1) What (apa)}

Apa yang akan disampaikan dalam tutorial ini?

Dalam tutorial akan disampaikan cara mencari ide dan merancang pembentukan pra produksi dalam berkarya komik dari segi 4 aspek yaitu: Outline, Character Design, Universe, dan Gimmick. 4 aspek yang memiliki standart industri komik digital.

\section{2) Who (siapa)}

Siapa yang merancang tutorial Comic Preparation dan kepada siapa tutorial ini ditujukan?

Tutorial ini dirancang oleh perancang berdasarkan pengalamanya sebagai komikus komik digital professional dan dilengkapi beberapa tips dari komikus yang lebih berpengalaman. Target audience primer dalam perancangan ini adalah komikus pemula usia produktif berkarya komik 15-30 tahun. Sedangkan target audience sekunder ini adalah seluruh masyarakat Indonesia yang tertarik untuk terjun di industri kreatif komik. 


\section{3) Where (dimana)}

Dimana tutorial Comic Preparation ini dilakukan?

Tutorial ini dilakukan di wilayah media sosial Instagram perkotaan Indonesia.

\section{4) When (kapan)}

Kapan tutorial ini dilakukan?

Tutorial ini tidak memiliki batasan waktu dalam peyampaianya di media sosial sampai saat diamana materi tutorial ini berada pada titik tujuan yang ditargetkan ataupun dimodifikasi.

\section{5) Why (kenapa)}

Kenapa tutorial ini menjadi penting?

Tutorial ini menjadi penting karena masalah komikus pemula menyangkut standarisasi industri komik digital dalam hal storytelling. Tutorial yang beredar di dunia maya dan buku masih dominan dengan tutorial fisik atau produksi berkarya komik, sangat jarang tutorial yang membahas tentang storytelling pra produksi berkarya komik. Sehingga komikus pemula memerlukan dukungan tutorial yang lebih menitikberatkan pada pra produksi.

\section{6) How (bagaimana)}

Bagaimana tutorial ini dilakukan?

tutorial ini dilakukan dengan membawa materi yang sederhana mudah dipahami serta beberapa contoh dari pelaku industri kreatif yang professional. Materi dalam tutorial akan disampaikan melalui media sosial Instagram berkala setiap hari kamis pukul 19.00 dan memanfaatkan fitur layout media sosial Instagram itu sendiri.

\section{b) Menentukan Konten Perancangan \\ TARGET AUDIENCE + TEORI = KONTEN}

Tahap penentuan konten perancangan dalam triadik DKV

ditentukan melalui proses menghubungkan antara titik landasan teori dengan target audience. Konten perancangan adalah isi perancangan itu sendiri, yang secara garis besar dapat dibagi menjadi isi pesan (pesan verbal dan pesan visual).

\section{1) Isi Tutorial}

Isi dari tutorial ini adalah materi pembentukan 4 aspek pra produksi berkarya komik, diantaranya adalah Outline; rancangan atau rancangan cerita komik, Character Design; desain karakter yang akan memainkan cerita komik, Universe; tempat dimana karakter memainkan cerita komik, dan Gimmick; ciri khas komik yang membuat komik itu unik.

\section{2) Bentuk Pesan}

Setelah isi tutorial dirumuskan, selanjutnya diolah ke dalam bentuk pesan yang menyangkut "Bagaimana menyampaikan kepada target audience". Penggambaran bentuk pesan dibuat berdasarkan pendekatan yang didasarkan pada motivasi-motivasi manusia. a. Pesan Verbal

Dasar tema (tema sentral) perancangan ini adalah dapat membentuk citra (image) yang diinginkan yaitu: "Komikus pemula memiliki kesadaran untuk merancang pra produksi komik dengan matang secara mudah dan sederhana namun berbobot sesuai dengan standar industri komik digital". Dari dasar tema kemudian dirumuskan judul tutorial yang singkat, padat, dan jelas. Judul tutorial pada perancangan ini adalah:

\section{"COMIC PREPARATION"}

Bahasa yang dipergunakan dalam copywriting pada perancangan tutorial ini menggunakan bahasa Inggris yang berarti dalam bahasa Indonesia "Persiapan dalam Komik". Dengan pemilihan gaya bahasa yang singkat, padat dan informatif sehingga mudah dipahami dan diingat oleh target audience.

b. Pesan Visual

1. Logo

Dalam tutorial ini diperlukan identitas visual untuk menandai tutorial tersebut. Aspek identitas tersebut divisualkan melalui sebuah logo tutorial. Rumusan logo tutorial Comic Preparation untuk komikus pemula adalah sebagai berikut:

\section{Logo berupa judul tutorial "Comic} Preparation"

- Jenis logo yang dipilih adalah logotype, yang didominasi oleh typografi menggunakan font Legwork Demo.

Sederhana/simple, sehingga memungkinkan diterapkan dalam berbagai media.

2. Ilustrasi 
Ilustrasi yang di gunakan adalah ilustrasi karakter komik dari komik SAMPANA karya komikus professional CIAYO COMIC adalah perancang dari perancangan ini. Illustrasi karakter komik digunakan untuk memikat target audience sebelum memasuki materi utama tutorial Comic Preparation serta memberi pesan bahwa pemateri memang sudah professional dalam bidang tersebut.

\section{Warna}

Warna yang digunakan menggunakan warna hitam pada latar belakang illustrasi dan tema warna karakter yang berbeda setiap chapter/materi yang akan disampaikan. Rumusan warna dominan tutorial Comic Preparation untuk komikus pemula pada setiap materi adalah sebagai berikut:

\section{Materi Outline}

Menggunakan dominan bewarna merah yang berarti berani, diharapkan untuk para komikus pemula untuk berani mencoba pada langkah pertama dalam tutorial Comic Preparation.

\section{口 Materi Design Character}

Menggungakan dominan bewarna kuning. Menurut Goethe warna kuning adalah warna yang memiliki derajat terang yang paling besar membuat warna kuning mampu menarik perhatian. Goethe juga mengatakan dalam aspek mental warna kuning juga memiliki kesan kreatif yang bisa memancing ide-ide baru. Diharapkan untuk para komikus pemula untuk kreatif dalam mencipatakan karakter-karakter komik yang menarik perhatian.

\section{$\checkmark \quad$ Materi Universe}

Menggunakan dominan bewarna hijau. Hijau adalah warna simbol dari alam, hal ini disesuaikan dengan materi pembentukan Universe/dunia dimana karakter menjalani cerita komik yang akan dibuat.

\section{- Materi Gimmick}

Menggunakan dominan bewarna ungu. Di alam, warna ungu jarang di jumpai, sehingga banyak yang mengkaitkan warna ungu dengan hal-hal yang dianggap berharga. Sesuai dengan materi yang disampaikan yaitu Gimmick yang berarti cirikhas dalam komik untuk membuatk komik menjadi unik atau berharga.

\section{Tipografi}

Tipografi yang digunakan dalam perancangan ini mengutamakan aspek readibility dan legibility yaitu aspek kemudahan target audience untuk mengenali masing-masing huruf dan memenuhi aspek keterbacaan. Sehingga perancang memilih font Lintel tanpa kait dan tanpa hiasan.

Sedangkan untuk logo desain tutorial Comic Preparation menggunakan huruf yang banyak digunakan untuk sound effect dalam komik agar lebih ekspresif, terkesan informal dan dekat dengan target audience. Font yang digunakan adalah font Legwork Demo. Berikut adalah jenis-jenis huruf yang digunakan dalam perancangan :

\section{LEGWORKDEMO ABCDEFGHIJKLMNOPORSTUVWXYZ}

\author{
Lintel \\ ABCDEFGHIJKLMNOPQRSTUVWXYZ \\ abcdefghijklmnopqrstuvwxyz
}

\section{Hasil dan Pembahasan}

\section{Menentukan Media Perancangan \\ PERMASALAHAN + TARGET AUDIENCE $=$ MEDIA}

Tahap penentuan media perancangan dalam triadik DKV ditunjukkan melalui proses menghubungkan titik permasalahan dengan target audience. Hal ini dimaksudkan bahwa media merupakan alat yang digunakan untuk menjangkau target audience, dalam misi membawa pesan-pesan tutorial. Media yang dipilih dalam perancangan ini merupakan baruan media konvensional yang bersinggungan dengan target audience perancangan. Oleh karena itu penentuan media berdasarkan hasil analisis consumer journey yang dilakukan kepada target audience perancangan dilakukan untuk mengetahui aktifitas keseharian target audience mulai dari bangun tidur sampai tidur lagi untuk mencari point of contact. Point of contact adalah kegiatan, tempat, waktu yang penuh dengan titik-titik (point) untuk menyapa atau melakukan kontak dengan target audience (Kasilo, 2008: 66). Analisis consumer journey telah dilakukan kepada: (1) Raka Gatra 
Sasmaya, mahasiswa berumur 22 tahun, dan (2) Maharani Septiana, freelance berumur 24 tahun. Media media yang menjadi point of contact berdasarkan analisis journey terhadap target audience perancangan adalah sebagai berikut :

(1) Media sosial yang diakses melalui Smartphone, (2) Komputer/Laptop, (3) Ruang kelas, dan (4) Kamar tidur di rumah. Setelah ditemukan mediamedia point of contact kemudian media media itu dibedakan berdasarkan media yang paling kuat/dekat dengan kehidupan target audience, media yang menjalin sinergi (sesuai kemampuan: waktu, tenaga, dan dana). Media yang dipilih untuk diwujudkan dalam perancangan ini adalah: (1) Infografis, dan (2) Poster.

\section{Infografis}

Media utama dalam perancangan ini adalah infografis. Infografis pada tutorial Comic Preparation untuk komikus pemula ini terdiri dari 4 seri infografis. 4 materi tutorial yang pernah dibawakan oleh perancang sebagai pengisi materi workshop dan seminar yang berhungungan dengan komik. Acara tersebut antara lain: (1) Novart, November 2017 di Universitas Negeri Malang, (2) 50th DKV UM, Februari 2018. Universitas Negeri Malang, (3) Kuliah tamu Universitas Machung, Maret 2018, Malang, (4) Comic Connect Yogyakarta, April 2018, Ciayo Comic, dan (5) Comic Connect Surabaya, Mei 2018, Ciayo Comic.

Materi yang akan disampaikan dengan konten yang berbeda namun berkesinambungan antara satu dengan yang lain. Keempat seri infografis dalam perancangan ini adalah: (1) Infografis "Outline", (2) Infografis "Character Design" (3) Infografis "Universe", dan (4) Infografis "Gimmick". Masing-masing infografis memiliki dua elemen dalam anatominya yaitu berupa illustrasi pengenalan dan materi yang disampaikan. Dua elemen infografis tersebut berbeda namun memiliki kesamaan dalam layout dan tema illustrasi. Keempat seri infografis ini nantinya akan ditampilkan secara online media sosial instagram berkala satu minggu satu seri. Infografis dalam bentuk digital dimuat dalam media sosial akun pribadi perancang yang juga sebagai komikus digital professional.

\section{Visualisasi}
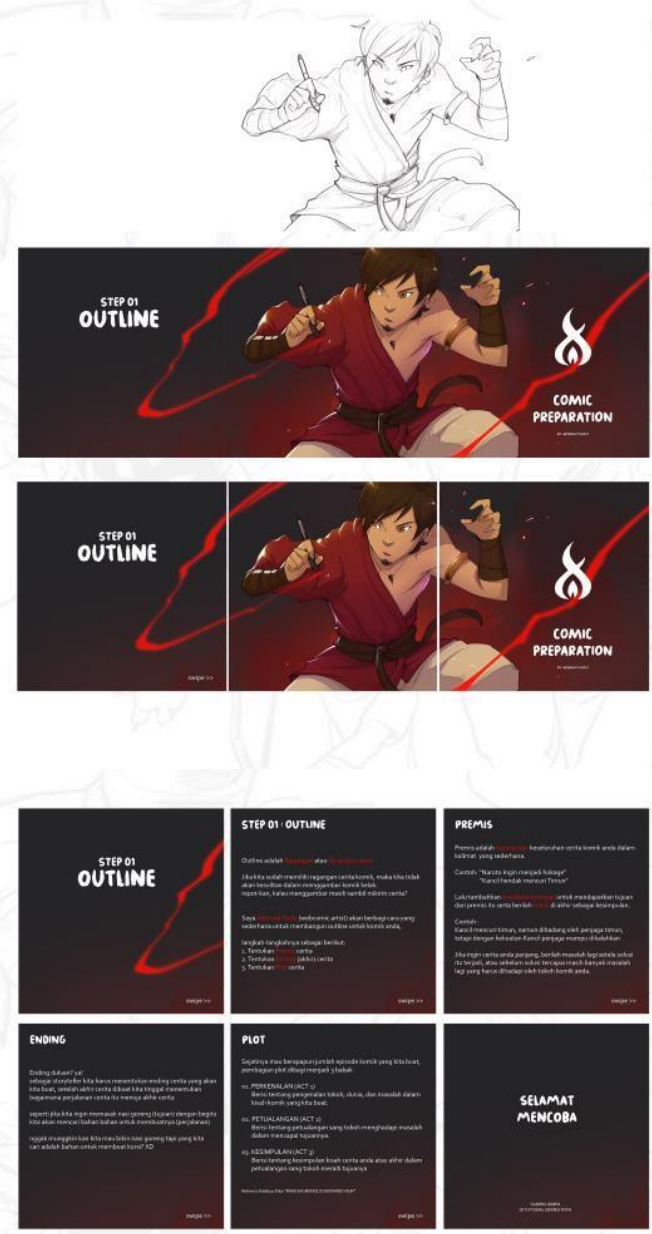

INFOGRAFIS OUTLNE

Menampilikan Illustrasi pembuka dengan dominan warna merah. dibuat sesuai dengan layout media sosial ins-

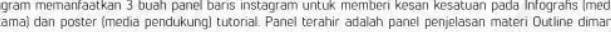
mikan infografis materi outtine berikutonya denga

Desain Infografis Outline 

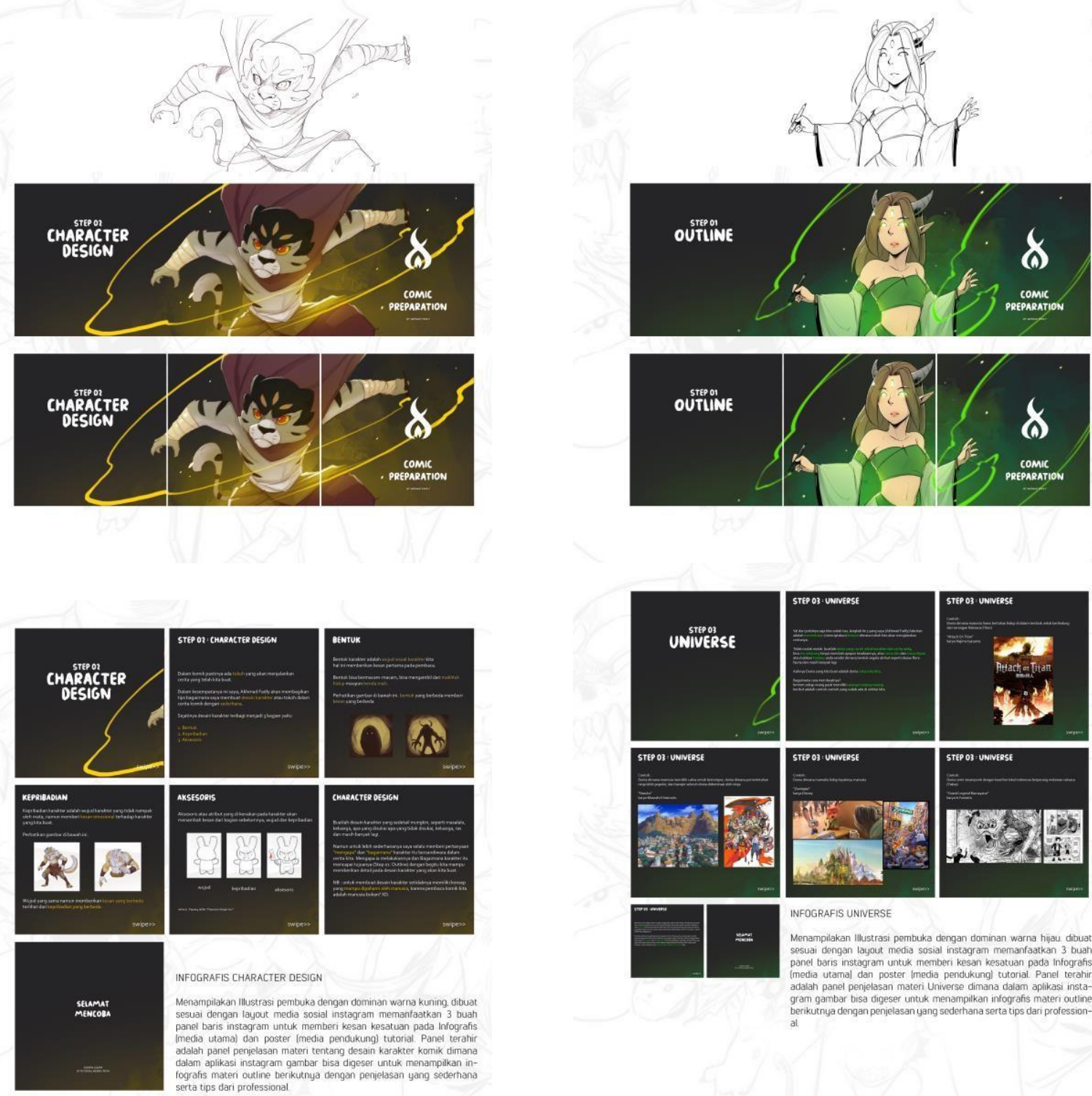

INFOGRAFIS CHARACTER DESIGN
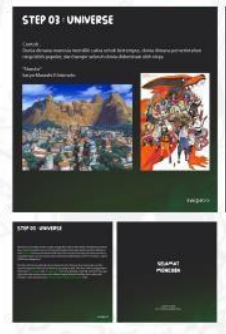

INFOGRAFIS UNIVERSE

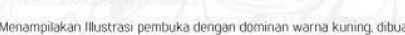

Menampiliakan lliustrasis pembukka dengan domininan warna kuning, dibuad
sesuai dengan layout media sosial instagram memantaatkan 3 buah

panel baris instagram untuk memberi kesan kesatuan pada Infografis
Imedia utamal dan poster (media penoukung) tutorial. Panel teratrits

gdalah panel penjelasan materi tentenang desain karacker komik dimar

fografis materi outine berikutnya dengan penjelasan yang sederhana

Desain Infografis Character Design

Desain Infografis Universe 

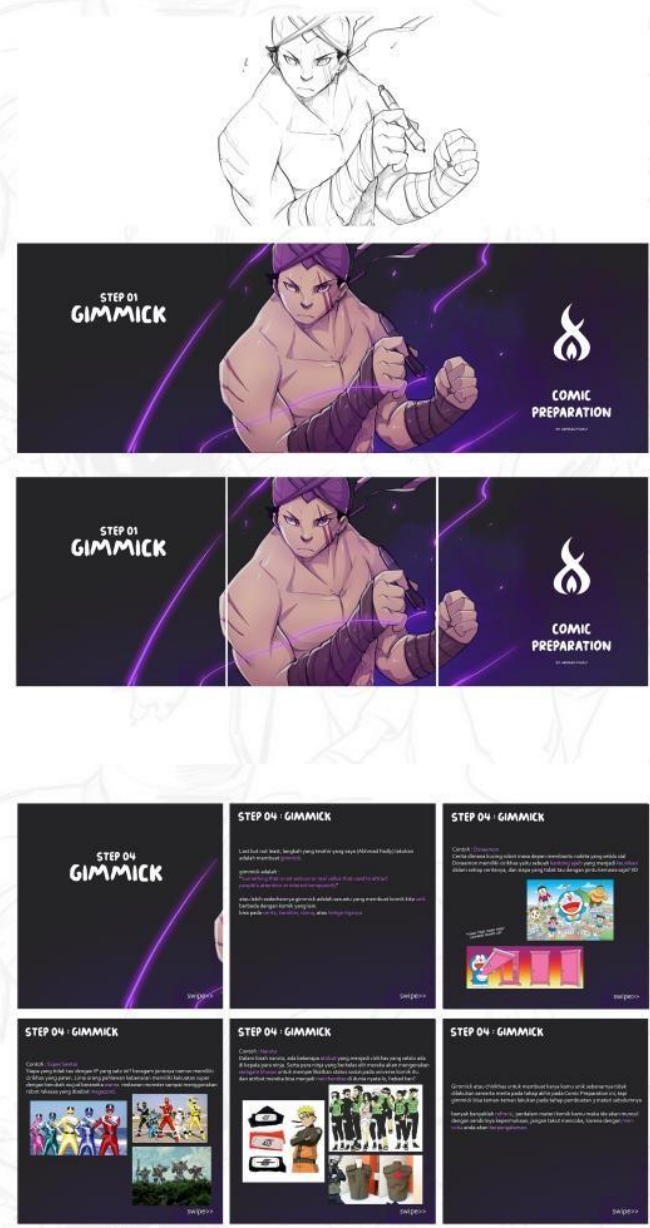

$\theta$

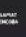

Menampilakan Illustrasi pembuka dengan dominan warna ungu dibuar
sesuai dengan Iayout media sosial instagram memanfaatkan 3 buar panel baris instagram untuk memberi kesan kesatuan pada Infográt
Imedia uramal dan poster Imedia pendukungl tutorial. Panel terat

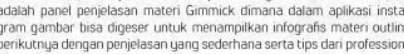

Desain Infografis Gimmick
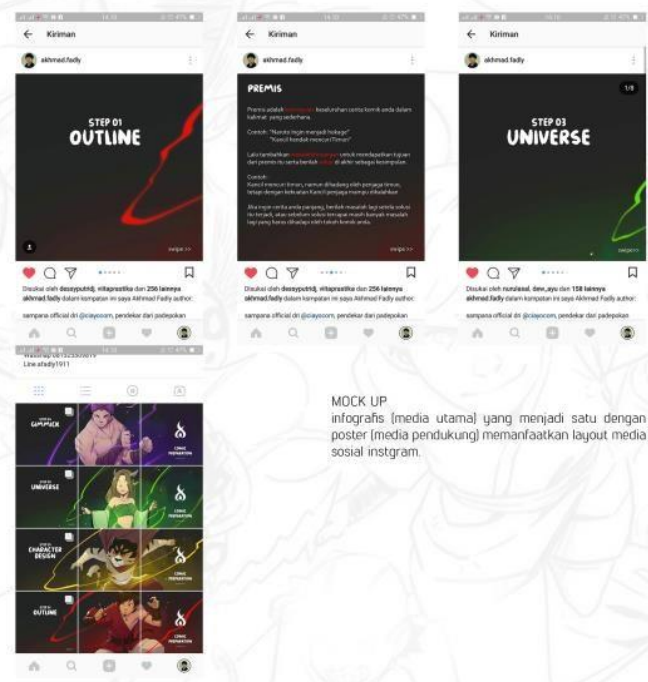
MOCK UP
infografis Imedia utamal yang meniadi satu dengan
poster (media pendukungl memanfaatkan layout media

Mockup Desain Pada Instagram

\section{Tanggapan Masyarakat}

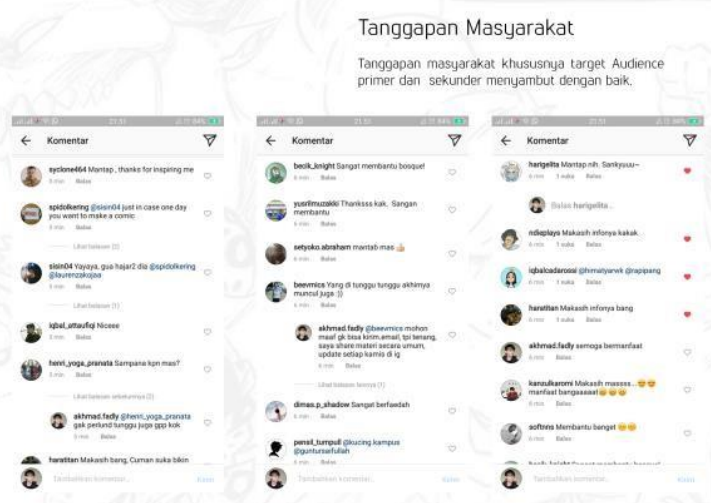

Tanggapan Masyarakat Sosial Media Terhadap Hasil Rancangan

\section{Kesimpulan}

Perkembangan komik di Indonesia dilihat dari beberapa fase semakin pesat perkembanganya. Hadirnya komik digital sebagai sarana berkarya komik juga banyak menggugah para kreator muda untuk bermunculan ke dunia perkomikan. Tidak hanya itu, platform komik digital atau webcomic juga menyanggupi untuk 
memberikan apresiasi dana yang cukup mumpuni kepada para komikus yang karyanya tayang di platform mereka. Semakin banyak komikus pemula bermunculan, namun tidak sedikit yang belum memenuhi standart yang baik untuk karya komik digital. Sebagaian besar kegagalan komikus pemula terletak pada bagian cerita atau storytelling. Untuk saat ini tutorial membuat komik khususnya dalam pengembangan storytelling sangat jarang.

Cerita atau storytelling adalah salah satu bagian terpenting dalam membuat komik. Perancangan tutorial Comic Preparation ini diharapkan mampu menjadi solusi permasalahan yang telah dipaparkan di atas. Comic Preparation ini disusun berdasarkan analisis $5 \mathrm{~W}+1 \mathrm{H}$ yang telah dilakukan. Tahap penentuan konten juga berdasarkan auidience atau target yang akan dicapai. Media utama dalam perancangan ini adalah infografis yang terdiri dari 4 seri infografis, 4 materi tutorial yang akan disampaikan dengan konten berbeda namun berkesinambungan antara satu dengan yang lainya. Keempat seri infografis ini ditampilkan secara online melalui media sosial instagram yang mampu mengunggah secara otomatis pada Facebook yang terkait. Hal ini bertujuan untuk memudahkan para pembaca yaitu para komikus muda.

\section{Daftar Pustaka}

Kusrianto, Adi. (2007). Pengantar Desain Komunikasi Visual. Jakarta: Andi

Rahmanadji, Didiek \& Harisman, Andi. (1991). Gambar Illustrasi. Malang: IKIP Malang.

Sularko, Herdi, Prawata, Victor N \& Widranata, Michael. (2008). HOW DO THEY THINK. Indonesia: Mosher

Tinarbuko, Sumbo. (2017). Membaca Tanda dan Makna Desain Komunikasi

Visual. Yogyakarta: Badan Penerbit ISI Yogyakarta

\section{Situs Web}

Informasitips.com. (2018). Arti WarnaWarna. Diakses 29 Mei 2018 dari http://www.informasitips.com/artiwarna

\section{Wawancanra}

Andik Prayogo, (44). Director ReOn Comic, Yogyakarta 2018

Mohammad Adesa P, (28).

Editor Ciayo Comic, Jakarta

2018 Sweta Kartika, (32).

Professional Comic Artist,

Bandung 2018 